\title{
Clinicopathological observation of primary lung enteric adenocarcinoma and its response to chemotherapy: A case report and review of the literature
}

\author{
LI LIN $^{1}$, CHUN-WEI XU ${ }^{2}$, BO ZHANG ${ }^{2}$, RONG-RUI LIU ${ }^{1}$, FEI-JIAO GE ${ }^{1}$, CHUAN-HUA ZHAO $^{1}$, \\ RU JIA ${ }^{1}$, QUAN-HONG QIN ${ }^{3}$, JELENA STOJSIC ${ }^{4}$, YAN WANG ${ }^{1}$ and JIAN-MING XU ${ }^{1}$ \\ Departments of ${ }^{1}$ Gastrointestinal Oncology and ${ }^{2}$ Pathology, Affiliated Hospital Cancer Center, Academy of \\ Military Medical Sciences, Beijing 100071; ${ }^{3}$ Department of Pathology, Tianjin First Center Hospital, \\ Tianjin 30000, P.R. China; ${ }^{4}$ Service of Histopathology, Clinical Centre of Serbia, Belgrade 11000, Serbia
}

Received February 15, 2015; Accepted September 1, 2015

DOI: $10.3892 /$ etm.2015.2864

\begin{abstract}
Primary lung enteric adenocarcinoma is a rare type of invasive lung carcinoma. Its morphology and immunohistochemistry are those of colorectal carcinoma, but there is no associated primary colorectal carcinoma. The present study describes the case of a 53-year-old female who presented with an irritating cough and a mass around the right sternoclavicular joint. Comprehensive evaluation revealed involvement of the mediastinum, lungs, right sternoclavicular joint and right kidney. Biopsies from the mediastinal and right sternoclavicular joint tumors showed features of adenocarcinoma. Immunohistochemistry was positive for cytokeratin (CK)20 and caudal type homeobox transcription factor 2, and negative for CK7, thyroid transcription factor-1 and napsin A. Genotypic analysis identified the expression of wild-type epidermal growth factor receptor, Kirsten rat sarcoma viral oncogene homolog, serine/threonine-protein kinase B-Raf and UDP-glucuronosyltransferase 1-1. There was no expression of echinoderm microtubule-associated protein-like 4-anaplastic lymphoma kinase and a moderate expression of excision repair cross-complementation group 1, ribonucleoside-diphosphate reductase large subunit and tubulin $\beta-3$ chain. A strong expression of thymidylate synthase and 677TC genotype expression of methylenetetrahydrofolate reductase was observed. Gastroscopy, enteroscopy, colorectal colonoscopy and positron emission tomography-computed tomography failed to find evidence of a gastrointestinal malignancy and primary lung enteric adenocarcinoma was diagnosed. The presence
\end{abstract}

Correspondence to: Professor Jian-Ming $\mathrm{Xu}$, Department of Gastrointestinal Oncology, Affiliated Hospital Cancer Center, Academy of Military Medical Sciences, 8 Dongda Street, Fengtai, Beijing 100071, P.R. China

E-mail: jmxu2003@yahoo.com

Key words: primary lung intestinal adenocarcinoma, diagnosis, clinicopathogical, chemotherapy of multiple metastases did not permit curative surgery. The patient was treated with 3 monthly cycles of the XELOX chemotherapy regimen; the response was poor with progression of supraclavicular lesions. Treatment was switched to the TP regimen for 4 monthly cycles, which resulted in a significant reduction in the size of the lung lesions; however, the supraclavicular lesion responded poorly to the treatment. The patient then received 2 cycles of the FOLFIRI regimen; however, the lung and right supraclavicular lesions progressed, causing increased right upper limb pain. The pain was alleviated by palliative surgery. Following surgery, the DP regimen was employed. Follow-up of the patient remains ongoing. The present findings suggest that the early diagnosis and treatment of primary lung enteric adenocarcinoma is likely to improve patient outcome.

\section{Introduction}

Carcinoma of the lung has the highest incidence and mortality rates among malignancies worldwide. Adenocarcinoma is the most common histological type of non-small cell lung carcinoma, accounting for approximately half of all lung carcinomas (1). The histological subtypes of lung adenocarcinoma differ greatly in their clinical and imaging features and genetics. The International Association for the Study of Lung Cancer, American Thoracic Society and European Respiratory Society jointly published an international multidisciplinary classification of lung adenocarcinoma in 2011 (2). The previous classifications were essentially pathological and based on histopathological type. The new classification drew on the additional expertise of oncologists, thoracic surgeons, radiologists, molecular biologists and others. The aim was to provide a more meaningful classification for planning treatment and guiding prognosis.

Enteric adenocarcinoma is a newly identified type of primary lung adenocarcinoma, which shares certain morphological and immunohistochemical features with colorectal adenocarcinoma, and is characterized by a $>50 \%$ intestinal differentiation of the tumor (2). It may also contain features of other histological subtypes of primary lung adenocarcinoma, 
such as the alveolar subtype. The immune phenotype can include the expression of one or more markers for colorectal carcinoma, including caudal type homeobox transcription factor 2 (CDX2), cytokeratin (CK)20 and mucin 2 (MUC2) (3-7). The expression of CK7 and thyroid transcription factor-1 (TTF-1) has been reported in up to $50 \%$ of intestinal adenocarcinomas. This can be helpful in differentiating intestinal adenocarcinoma from metastatic colorectal carcinoma (3). The present study reports the case of a 53-year-old female patient diagnosed with primary lung enteric adenocarcinoma, and includes a review of the relevant literature. The protocol in the present study was reviewed and approved by the Human Clinical and Research Ethics Committees. This patient provided written informed consent.

\section{Case report}

In early February 2014, a 53-year-old female was admitted to the People's Hospital of Zhengding (Zhengding, China) with a 1-year history of an intermittent dry cough, for which no prior treatment had been received. The patient was not, and had never been a smoker. She also reported pain in her right shoulder and back, and had a poorly defined mass in the region of her right sternoclavicular joint, which she reported to be growing slowly. At presentation the mass measured $5 \mathrm{~cm}$ in diameter.

A computed tomography (CT) scan revealed a mass in the mediastinum and more masses in the lungs, all of which were suspected to be malignant. The bronchoscopy was normal. A biopsy of the mediastinal mass was conducted under ultrasound control. Histological examination revealed a solid, moderately differentiated adenocarcinoma, which was infiltrating connective tissue in the left side of the mediastinum. Immunohistochemical staining was performed with a range of primary antibodies obtained from Zymed Corporation, Inc. (San Francisco, CA, USA). The neoplastic cells stained positively for CDX2 (rabbit; clone, EP25), carcinoembryonic antigen (CEA; mouse; clone, CEA31), CK20 (rabbit; clone, EP23), Villin (rabbit; clone, EP163) and cancer antigen 15-3 (CA15-3; mouse; clone, DF3), and negatively for TTF-1 (mouse; clone, SPT24), noval aspartic proteinase of the pepsin family A (mouse; clone, IP64), human epidermal growth factor-2 (Her-2; mouse; clone, EP3), CK7 (mouse; clone, EP16), p63 (mouse; clone, UMAB4) and CA19-9 (mouse; clone, C241; 5:1:1:4) (all dilutions, 1:100) (Fig. 1). On the basis of these findings, metastatic colorectal carcinoma was excluded. Cranial magnetic resonance imaging (MRI), pelvic CT (Fig. 2), gastroscopy, enteroscopy colorectal colonoscopy and positron emission tomography-CT (PET-CT) were performed. They failed to find evidence of a primary gastrointestinal tumor. A bone scan revealed metastasis in the right sternoclavicular joint. Abdominal MRI revealed a mass in the upper pole of the right kidney and multiple nodules in both kidneys. An abdominal PET-CT scan did not identify any abnormally hypermetabolic lesions, double renal parenchyma, double multiple high metabolic nodules or neoplasms in the gastrointestinal tract.

Tumor histology was reviewed by pathologists at four different institutions, who were in agreement that the primary tumor was likely to be a malignancy of the digestive tract. The institutions were the Departments of Pathology at the Cancer
Table I. Details of XELOX, TP and FOLFIRI chemotherapy.

\begin{tabular}{lccc}
\hline Regimen & Dosage $\left(\mathrm{mg} / \mathrm{m}^{2}\right)$ & $\begin{array}{c}\text { Method of } \\
\text { administration }\end{array}$ & Day \\
\hline XELOX & & & \\
Oxaliplatin & 130 & i.v. & 1 \\
Capecitabine & 1,000 & p.o. b.i.d. & $1-14$ \\
TP & & & \\
Paclitaxel & 175 & i.v. & 1 \\
Cisplatin & 20 & i.v. & $1-3$ \\
FOLFIRI & & & \\
Irinotecan & 180 & i.v. & 1 \\
Leucovorin & 400 & i.v. & 1 \\
5-Fu & 400 & bolus i.v. & 1 \\
5-Fu & 2,400 & c.i.v. 46 h & $1-2$ \\
\hline
\end{tabular}

i.v., intravenous; p.o., oral; c.i.v, continuous intravenous; b.i.d., twice per day.

Institute \& Hospital, Chinese Academy of Medical Sciences; Peking Union Medical College Hospital; People's Liberation Army General Hospital; and the Affiliated Hospital Cancer Center, Academy of Military Medical Sciences, respectively (all institutions in Beijing, China). Cytogenetic studies of the tumor tissue were undertaken using tumor markers obtained from Amoy Diagnostics Co., Ltd. (Xiamen, China). The genotypic analysis identified the expression of wild-type epidermal growth factor receptor (EGFR), Kirsten rat sarcoma viral oncogene homolog (K-ras), serine/threonine-protein kinase B-Raf (BRAF) and UDP-glucuronosyltransferase 1-1 (UGT1A1). There was noexpression of echinoderm microtubule-associated protein-like 4-anaplastic lymphoma kinase (EML4-ALK) and moderate expression of excision repair cross-complementation group 1 (ERCC1), ribonucleoside-diphosphate reductase large subunit (RRM1) and tubulin $\beta-3$ chain (TUBB3). Strong expression of thymidylate synthase (TYMS) and 677TC genotype expression of methylenetetrahydrofolate reductase (MTHFR) was observed.

Initially, the patient was reluctant to undertake targeted therapy instead of chemotherapy for economic reasons; however, the tumor continued to develop despite the chemotherapy. The patient subsequently chose to undergo targeted therapy through genetic testing. Unfortunately, the patient did not identify a suitable candidate target for targeted therapy following genetic testing, so the patient was not suitable for targeted therapy. As an alternative treatment, the patient's chemotherapy regimen was altered. Therefore, the patient was treated with rescue chemotherapy comprising 3 monthly cycles of oxaliplatin and capecitabine (XELOX regimen). The response was poor, with supraclavicular nodes being noted following the second cycle (Table I and Fig. 1). The patient was switched to docetaxel and cisplatin (the TP regimen) for 4 monthly cycles (Table I and Fig. 1). The response was good in terms of the pulmonary lesions and the level of CEA, which fell from a pre-treatment level of 8,327 to $2,248 \mathrm{ng} / \mathrm{ml}$; however, the supraclavicular lesions progressed further and so 


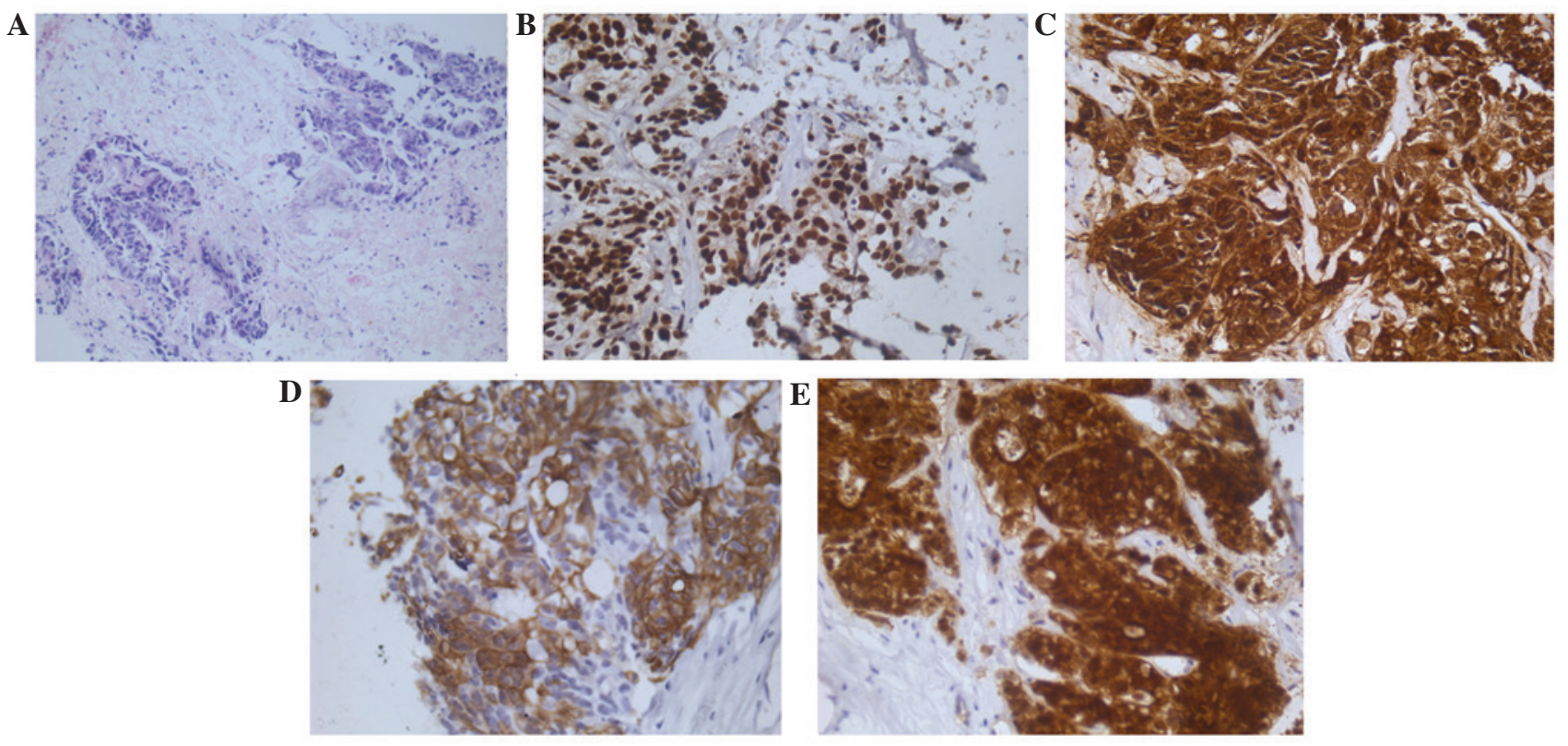

Figure 1. Hematoxylin and eosin staining and immunohistochemistry with CDX2, CEA, CK20 and villin. (A) Histological examination showed a moderately differentiated adenocarcinoma infiltrating fibrous connective tissues (magnification, x200); (B-E) Immunohistochemical staining for the expression of CDX2, CEA, CK20 and villin in the neoplastic cells, observed using anti-CDX2, anti-CEA, anti-CK20 with slight hematoxylin counterstain (magnification, x400). CDX2, caudal type homeobox transcription factor 2; CEA, carcinoembryonic antigen; CK, cytokeratin.

the treatment of the patient was changed again, this time to folinic acid, florouracil and irinotecan (the FOLFIRI regimen), which was administered in 2 monthly cycles. Neither the lung lesions nor the supraclavicular lesions responded to this regimen. The latter was associated with more severe upper limb pain and was treated with surgical excision 9 months following the first presentation, which relieved the pain. Two months following the surgery, lung lesion (disease stable). The patient was subsequently treated with docetaxel and cisplatin (the DP regimen) and continues to be followed up (Table I and Fig. 1).

\section{Discussion}

Primary lung enteric adenocarcinoma is defined in the 2011 classification of lung adenocarcinoma as a type of invasive lung carcinoma (2). It is characterized by $>50 \%$ intestinal differentiation of the tumor, with no evidence of a primary digestive tract tumor. Based on immunohistochemistry, two types of lung adenocarcinoma with intestinal differentiation and morphology can be distinguished: Lung adenocarcinoma with intestinal differentiation and $\geq 1$ positive intestinal-type differentiation marker (CK20, CDX2, MUC-2 or villin), and lung adenocarcinoma with intestinal morphology but negative for intestinal-type differentiation markers (8-10). Primary lung enteric adenocarcinoma has immunohistochemical similarities with metastatic colorectal cancer. Its diagnosis requires the exclusion of a primary enteric tumor, which, in turn, requires gastroscopy and enteroscopy.

Details of the present and 30 previously reported cases of primary lung intestinal adenocarcinoma (11-19) are shown in Table II. All 31 cases expressed CK7, CK20 or TTF-1; 26 (84\%), 13 (42\%) and 14 (45\%) cases, respectively, were positive for each marker. At least 20 cases were tested for the markers CDX2, napsin A and MUC2. Seventeen out of $29(59 \%), 3$ out of $20(15 \%)$ and 9 out of $26(35 \%)$ cases, respectively, exhibited a positive expression. Eleven out of $14(79 \%)$ patients were positive for villin expression. All cases positive for TTF-1 or napsin A expression were also positive for CK7 expression. Eleven cases were positive for both CK20 and CDX2 expression. Seven out of 26 (27\%) cases that were tested for the intestinal-type markers CK20, CDX2 and MUC2 were negative for the expression of all three proteins. Five out of $26(19 \%)$ cases were positive for the intestinal-type markers CK20 and CDX2, but negative for the lung adenocarcinoma immune markers CK7 and TTF-1. This indicates that, whilst the latter are important markers assisting the diagnosis of lung adenocarcinoma, false negatives do occur $(20,21)$.

The main symptoms of the present patient were an intermittent dry cough and a right-sided supraclavicular mass. The patient did not exhibit any gastrointestinal symptoms such as nausea, vomiting, abdominal pain, diarrhea, constipation or bloody stools. The chest CT scan revealed lesions in the mediastinum, lungs and right supraclavicular region. $\mathrm{CT}$ and PET-CT scans of the large and small intestine and pelvic cavity were performed. No evidence of a primary gastrointestinal tract tumor was found, although multiple metastases were observed in the right kidney. Similarly, gastroscopy, enteroscopy and colorectal colonoscopy did not find evidence of a gastrointestinal malignancy. The diagnosis of a primary lung enteric adenocarcinoma was made on the basis of the aforementioned clinical, imaging and pathological findings.

With regard to molecular markers for primary lung enteric adenocarcinoma, the mutation rates for EGFR, K-ras, EML4-ALK and BRAF are $\sim 50,20,5$ and $2 \%$, respectively $(22,23)$. In colorectal cancer, the mutation rates for K-ras and BRAF are 30 and 9\%, respectively (24); however, in the present case the EGFR, K-ras and BRAF genes that 


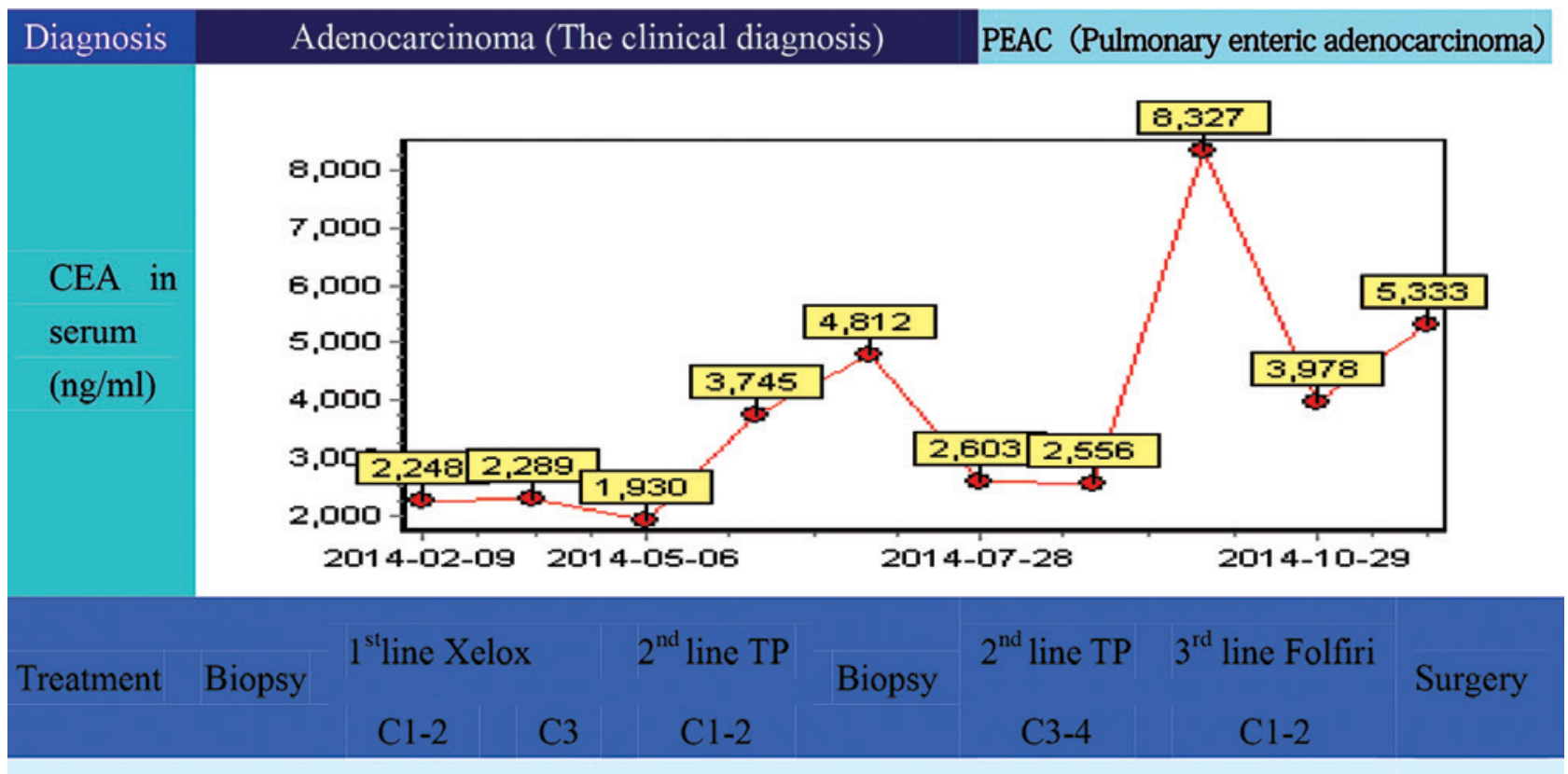

Timeline Feb Mar-Apr May Jun-Jul Aug Aug-Sep Oct Nov
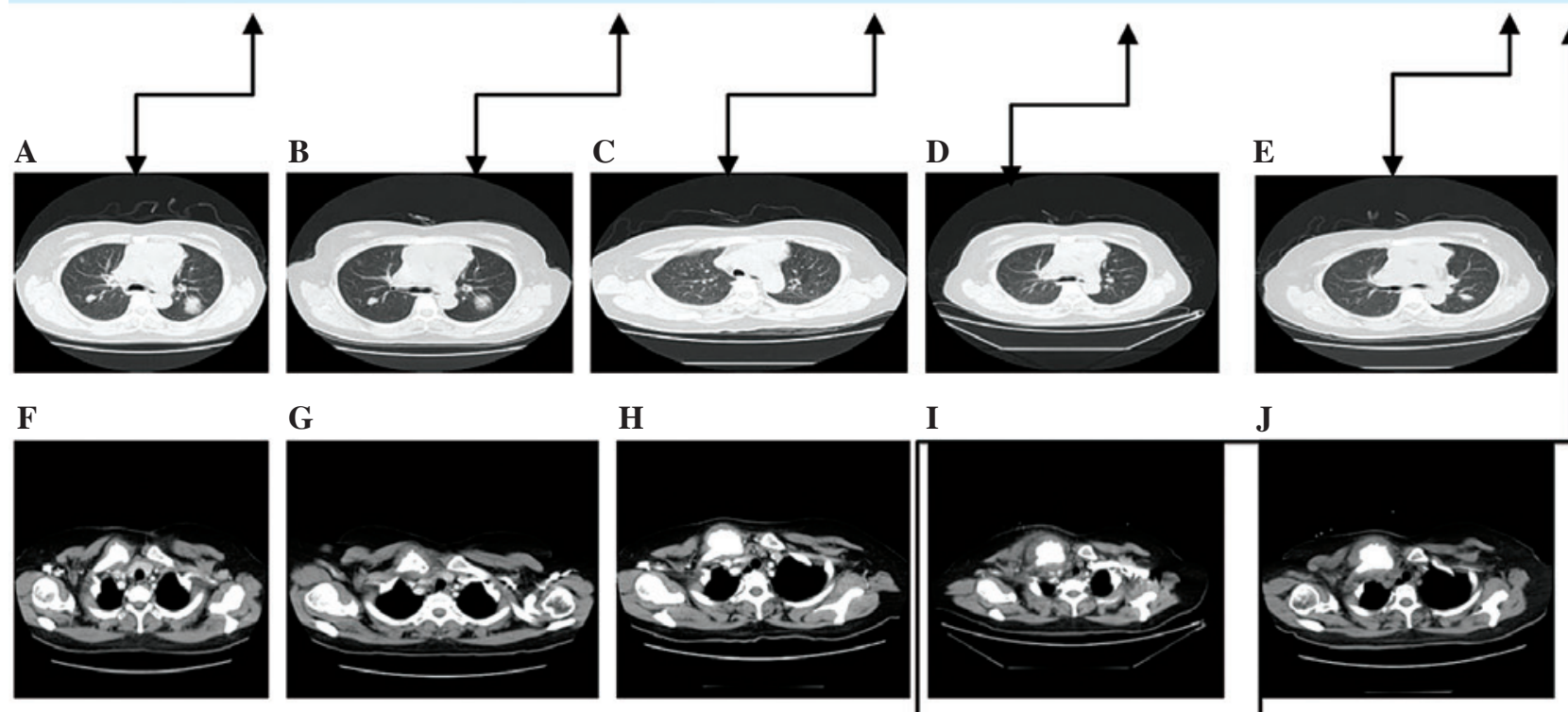

$\mathbf{J}$

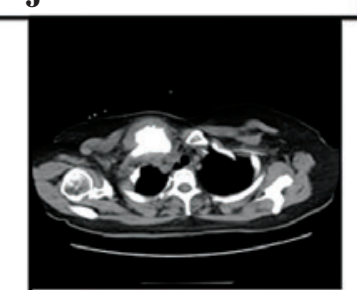

$\mathbf{K}$

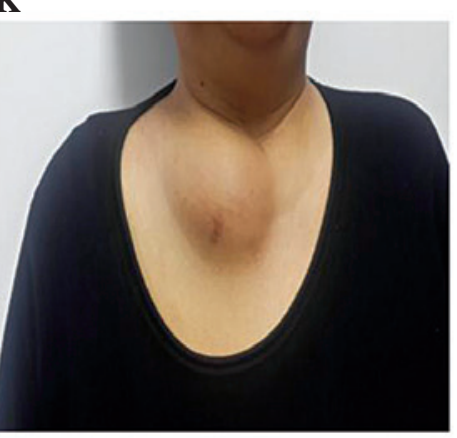

$\mathbf{L}$

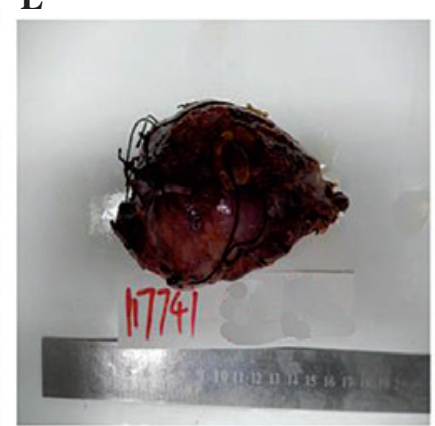

Figure 2. Treatment of lung enteric adenocarcinoma with different chemotherapy regimens and results of monitoring of the CEA levels. The color-coded boxes to the left of each panel explain the relevant data. (A-E) Lung CT scans from (A) February, (B) May, (C) August, (D) September and (E) November 2014. (F-J) CT scans of the mediastinum from (F) February, (G) May, (H) August, (I) September and (J) November 2014. (K and L) Supraclavicular neoplasm (K) preoperatively and (L) postoperatively. CEA, carcinoembryonic antigen; CT, computed tomography; C, cycle. 
Table II. Review of all literature for primary lung enteric adenocarcinoma (31 cases).

Clinical

follow-up

results

(month)

First author (ref.), Tumor size

Immunohistochemical results gender/age $/$ smoking $(\mathrm{mm}) /$ site

CK7 CK20 TTF-1

CDX2 Napsin A MUC2

Villin

Stage

Inamura et al (11)

M/NA/yes
M/NA/yes
F/NA/yes
M/NA/yes
M/NA/yes
M/NA/yes
M/NA/yes

Yousem (12)

F/74/yes
F/70/yes
M/82/yes
F/63/yes
F/73/yes
F/57/yes

Maeda et al (13)

M/69/NA

Li et al (14)

$$
\text { F/51/yes }
$$

Hatanaka et al (15)

$$
\text { F/51/no }
$$

Lin et al (16)

$$
\text { F/61/no }
$$

Stojsic et al (17)

$$
\mathrm{M} / 24 / \mathrm{NA}
$$

F/26/NA

Qureshi et al (18)

F/61/NA
F/61/no

Wang et al (19)

\begin{tabular}{|c|c|c|}
\hline 50/RUL & + & - \\
\hline 40/LUL & + & - \\
\hline 26/LLL & + & $\mathrm{p}+$ \\
\hline 34/RLL & + & $\mathrm{p}+$ \\
\hline 23/RLL & + & + \\
\hline 17/RUL & + & - \\
\hline 39/LUL & + & - \\
\hline
\end{tabular}

$$
\begin{aligned}
& \text { M/65/no } \\
& \text { F/56/no } \\
& \text { M/60/yes } \\
& \text { F/63/yes } \\
& \text { F/65/yes } \\
& \text { M/74/yes } \\
& \text { M/61/yes } \\
& \text { F/34/no } \\
& \text { F/63/yes }
\end{aligned}
$$

Present case

F/53/no

$\begin{array}{cc}+ & \\ + & \\ - & \mathrm{p}+ \\ - & \mathrm{p}+ \\ - & \\ \mathrm{p}+ & \mathrm{p}+ \\ - & \end{array}$

-
+
$\mathrm{p}+$
$\mathrm{p}+$
+
$\mathrm{p}+$
-

\begin{abstract}
36/RUL
\end{abstract} 17/RUL 65/RUL 15/RUL

\section{0/LLL}

20/RUL

$\begin{array}{lll}+ & - & \\ + & - & \\ + & - & \\ + & - & \\ + & - & \\ + & -\end{array}$

+
+
$\mathrm{p}+$
+
+
+

25/RLL

33/LLL

30/LLL and 10/RUL

50/RML

60/LLL

60/LLL

$\begin{array}{lll}\mathrm{MB} & + & + \\ 60 / \mathrm{RML} & + & \mathrm{p}+\end{array}$

$-\quad N$

$\stackrel{+}{\text { NA }}$

NA

NA

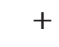

$\mathrm{T}_{3} \mathrm{~N}_{0} \mathrm{M}_{0}$

$\begin{array}{lclll}\text { NA } & - & \mathrm{NA} & \mathrm{T}_{2} \mathrm{~N}_{1} \mathrm{M}_{0} & \mathrm{D}(26) \\ \mathrm{NA} & - & \mathrm{NA} & \mathrm{T}_{2} \mathrm{~N}_{1} \mathrm{M}_{0} & \mathrm{D}(18) \\ \mathrm{NA} & - & \mathrm{NA} & \mathrm{T}_{2} \mathrm{~N}_{0} \mathrm{M}_{0} & \mathrm{D}(5) \\ \mathrm{NA} & - & \mathrm{NA} & \mathrm{T}_{1} \mathrm{~N}_{0} \mathrm{M}_{0} & \mathrm{~A}(7) \\ \mathrm{NA} & \mathrm{p}+ & \mathrm{NA} & \mathrm{T}_{2} \mathrm{~N}_{0} \mathrm{M}_{0} & \mathrm{~A}(3) \\ \mathrm{NA} & - & \mathrm{NA} & \mathrm{T}_{2} \mathrm{~N}_{0} \mathrm{M}_{0} & \mathrm{~A}(2)\end{array}$

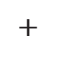

-

$+\quad \mathrm{T}_{2} \mathrm{~N}_{0} \mathrm{M}_{0}$

$+$

23/RLL 30/RUL

$+$

$\begin{array}{cc}\mathrm{p}+ & + \\ + & + \\ + & + \\ - & - \\ + & - \\ - & - \\ - & + \\ - & + \\ - & +\end{array}$

$\mathrm{NA} \quad \mathrm{NA} \quad \mathrm{T}_{\mathrm{x}} \mathrm{N}_{\mathrm{x}} \mathrm{M}_{1}$

NA

$\begin{array}{llll}\mathrm{NA} & \mathrm{NA} & \mathrm{NA} & \mathrm{T}_{\mathrm{x}} \mathrm{N}_{\mathrm{x}} \mathrm{M}_{1} \\ \mathrm{NA} & \mathrm{NA} & + & \mathrm{T}_{3} \mathrm{~N}_{0} \mathrm{M}_{0}\end{array}$
27/RUL

20/RUL

15/LLL

60/RUL

48/RUL

33/RUL

$\begin{array}{ll}+ & - \\ + & - \\ + & - \\ + & - \\ + & - \\ + & - \\ + & \mathrm{p} \\ + & - \\ + & +\end{array}$

+
-
-
+
-
+
-
-
-

$\begin{array}{cccl}- & - & \mathrm{T}_{1} \mathrm{~N}_{1} \mathrm{M}_{0} & \mathrm{D}(36) \\ + & - & \mathrm{T}_{1} \mathrm{~N}_{0} \mathrm{M}_{0} & \mathrm{~A}(27) \\ - & + & \mathrm{T}_{2} \mathrm{~N}_{0} \mathrm{M}_{0} & \mathrm{~A}(39) \\ \mathrm{p}+ & + & \mathrm{T}_{1} \mathrm{~N}_{0} \mathrm{M}_{0} & \mathrm{~A}(43) \\ - & + & \mathrm{T}_{2} \mathrm{~N}_{1} \mathrm{M}_{0} & \mathrm{D}(12) \\ + & - & \mathrm{T}_{1} \mathrm{~N}_{0} \mathrm{M}_{0} & \mathrm{~A}(23) \\ - & + & \mathrm{T}_{2} \mathrm{~N}_{3} \mathrm{M}_{0} & \mathrm{D}(7) \\ \mathrm{p}+ & + & \mathrm{T}_{2} \mathrm{~N}_{1} \mathrm{M}_{0} & \mathrm{~A}(22) \\ - & \mathrm{p}+ & \mathrm{T}_{2} \mathrm{~N}_{0} \mathrm{M}_{0} & \mathrm{~A}(6)\end{array}$

$\mathrm{MB}$

$+\quad \mathrm{T}_{2} \mathrm{~N}_{1} \mathrm{M}_{1}$

A (12)

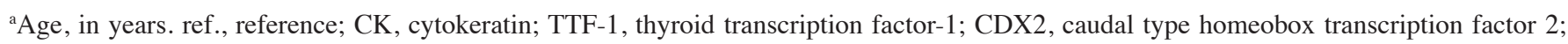
napsin A, noval aspartic proteinase of the pepsin family A; MUC2, mucin 2; M, male; F, female; NA, not available; RLL, right lower lobe; RUL, right upper lober; LLL, left lower lobe; LUL, left upper lobe; RML, right middle lobe; MB, multiple bilateral; D, deceased; A, alive; p, partially. 
were expressed were all wild-type and no expression of the EML4-ALK fusion gene was identified. These findings indicate that the patient was not a suitable candidate for targeted drug therapy.

To date, the only chemotherapy regimen reported to be successful in the treatment of this tumor is pemetrexed and carboplatin given for 4 cycles (14). The side-effects of this regimen have been said to be tolerable, with a stable disease response. There are no reports suggesting that genotyping helps predict the response to chemotherapy. At the 2013 meeting of the American Society of Clinical Oncology, the Spanish Lung Cancer Group reported that the expression status of ERCC1 and RRM1 is not helpful for individualizing chemotherapy regimens (25). At the 2013 World Conference on Lung Cancer, Bonanno et al reported that neither breast cancer 1 nor receptor-associated protein 80 assisted in predicting the response to individualized chemotherapy in phase III randomized controlled studies (26). Therefore, it is not currently possible to implement individualized chemotherapy based on the expression of specific genes; however, certain reports have suggested correlations between gene expression and drug efficacy (27-29). Retrospective measurement of gene expression in those sensitive to chemotherapy demonstrated moderate expression of ERCC1, TUBB3 and RRM1, and high expression of TYMS, wild-type UGT1A1 and MTHFR TC, microsatellite stable. These results suggest the likelihood of a particular sensitivity to taxane and platinum drugs, and reduced sensitivity to fluoropyrimidine. Clinical practice tends to confirm this (27-29).

The majority of the previously reported cases of primary lung intestinal adenocarcinoma had localized disease without metastases and were treated surgically. The present case, however, had advanced disease, which was not amenable to curative surgery. The patient received palliative treatment instead, both with surgery and with four different chemotherapy regimens. The first and third chemotherapy regimens used in the present case are usually selected for colorectal carcinomas, whilst the second and fourth regimens are mainly used to treat non-small cell carcinomas of the lung. Detailed evaluation showed that the TP regimen produced an clear response, shown by a reduction in the level of CEA.

Standard chemotherapy for colorectal carcinoma comprises oxaliplatin, irinotecan and fluorouracil $(30,31)$. The patient of the present case had a poor response to chemotherapeutic drugs used to treat metastatic colorectal cancer. Taxane combined with platinum is commonly used as the first line chemotherapy for non-small cell lung carcinoma. This has shown limited efficacy in preclinical studies in colorectal carcinoma, and for that reason the Federal Drug Administration does not recommend this regimen for the treatment of colorectal carcinomas (32). In the present case, the patient's lung lesions responded well to taxane combined with platinum, which was shown by a significant reduction in their size. No change, however, was observed in the size of the mediastinal and renal metastases. The progression of the right supraclavicular mass, despite chemotherapy, was probably a consequence of the heterogeneity of the tumor.

In conclusion, the present study reports a case of metastatic carcinoma with the primary tumor being enteric carcinoma of the lung, and includes details of its response to chemotherapy regimens. The patient presented with mediastinal, lung and right supraclavicular masses, but with no evidence of a gastrointestinal malignancy. She was treated with four different chemotherapy regimens, namely, XELOX, TP, FOLFIRI and DP. A significant reduction in the size of the lung lesions was observed during the second regimen. Further consideration is required when deciding on a chemotherapy regimen for metastatic enteric carcinoma of the lung, and future reports of individual cases of this rare tumor could considerably assist the decision-making process.

\section{References}

1. Siegel R, Ma J, Zou Z and Jemal A: Cancer statistics, 2014. CA Cancer J Clin 64: 9-29, 2013.

2. Travis WD, Brambilla E, Noguchi M, Nicholson AG, Geisinger KR, Yatabe Y, Beer DG, Powell CA, Riely GJ, Van Schil PE, et al: International Association for the Study of Lung Cancer/American Thoracic Society/European Respiratory Society: International multidisciplinary classification of lung adenocarcinoma. J Thorac Oncol 6: 244-285, 2011.

3. Chhieng DC, Cangiarella JF, Zakowski MF, Goswami S, Cohen JM and Yee HT: Use of thyroid transcription factor 1, PE-10 and, cytokeratins 7 and 20 in discriminating between primary lung carcinomas and metastatic lesions in fine-needle aspiration biopsy specimens. Cancer 93: 330-336, 2001.

4. Ueno T, Linder S and Elmberger G: Aspartic proteinase napsin is a useful marker for diagnosis of primary lung adenocarcinoma. Br J Cancer 88: 1229-1233, 2003.

5. Barbareschi M, Murer B, Colby TV, Chilosi M, Macri E, Loda M and Doglioni C: CDX-2 homeobox gene expression is a reliable marker of colorectal adenocarcinoma metastases to the lungs. Am J Surg Pathol 27: 141-149, 2003.

6. Ho SB, Shekels LL, Toribara NW, Kim YS, Lyftogt C, Cherwitz DL and Niehans GA: Mucin gene expression in normal, preneoplastic and neoplastic human gastric epithelium. Cancer Res 55: 2681-2690, 1995.

7. Lau SK, Weiss LM and Chu PG: Differential expression of MUC1, MUC2 and MUC5AC in carcinomas of various sites: An immunohistochemical study. Am J Clin Pathol 122: 61-69, 2004.

8. Min KW: Two different types of carcinoid tumors of the lung: Immunohistochemical and ultrastructural investigation and their histogenetic consideration. Ultrastruct Pathol 37: 23-35, 2013.

9. Travis WD, Brambilla E, Noguchi M, Nicholson AG, Geisinger K, Yatabe Y, Ishikawa Y, Wistuba I, Flieder DB, Franklin W, et al: Diagnosis of lung adenocarcinoma in resected specimens: Implications of the 2011 International association for the Study of lung Cancer/American Thoracic Society/European Respiratory Society classification. Arch Pathol Lab Med 137: 685-705, 2013.

10. Ou SH, Kawaguchi T, Soo RA and Kitaichi M: Rare subtypes of adenocarcinoma of the lung. Expert Rev Anticancer Ther 11: 1535-1542, 2011.

11. Inamura K, Satoh Y, Okumura S, Nakagawa K, Tsuchiya E, Fukayama M and Ishikawa Y: Pulmonary adenocarcinomas with enteric differentiation: Histologic and immunohistochemical characteristics compared with metastatic colorectal cancers and usual pulmonary adenocarcinomas. Am J Surg Pathol 29: 660-665, 2005

12. Yousem SA: Pulmonary intestinal-type adenocarcinoma does not show enteric differentiation by immunohistochemical study. Mod Pathol 18: 816-821, 2005.

13. Maeda R, Isowa N, Onuma $\mathrm{H}$ and Miura H: Pulmonary intestinal-type adenocarcinoma. Interact Cardiovasc Thorac Surg 7: 349-351, 2008.

14. Li HC, Schmidt L, Greenson JK, Chang AC and Myers JL: Primary pulmonary adenocarcinoma with intestinal differentiation mimicking metastatic colorectal carcinoma. Am J Clin Pathol 131: 129-133, 2009.

15. Hatanaka K, Tsuta K, Watanabe K, Sugino K and Uekusa T: Primary pulmonary adenocarcinoma with enteric differentiation resembling metastatic colorectal carcinoma: A report of the second case negative for cytokeratin 7. Pathol Res Pract 207: 188-191, 2011.

16. Lin D, Zhao Y, Li H and Xing X: Pulmonary enteric adenocarcinoma with villin brush border immunoreactivity: A case report and literature review. J Thorac Dis 5: E17-E20, 2013. 
17. Stojsic J, Kontic M, Subotic D, Popovic M, Tomasevic D and Lukic J: Intestinal type of lung adenocarcinoma in younger adults. Case Rep Pulmonol 2014: 282196, 2014.

18. Qureshi A and Furrukh M: Enteric adenocarcinoma lung: A rare presentation in an Omani woman. BMJ Case Rep 25 : doi:10.1136/bcr-2012-007667, 2013.

19. Wang CX, Liu B, Wang YF, Zhang RS, Yu B, Lu ZF, Shi QL and Zhou XJ: Pulmonary enteric adenocarcinoma: A study of the clinicopathologic and molecular status of nine cases. Int J Clin Exp Pathol 7: 1266-1274, 2014.

20. Remo A, Zanella C, Pancione M, Astati L, Piacentini P, Cingarlini S, Bonetti A, Micheletto C, Talamini A, Chilosi M, et al: Lung metastasis from TTF-1 positive sigmoid adenocarcinoma. Pitfalls and management. Pathologica 105: 69-72, 2013.

21. Sullivan LM, Smolkin ME, Frierson HFJr and Galgano MT: Comprehensive evaluation of CDX2 in invasive cervical adenocarcinomas: Immunopositivity in the absence of overt colorectal morphology. Am J Surg Pathol 32: 1608-1612, 2008.

22. Tsao MS and Fraser RS: Primary pulmonary adenocarcinoma with enteric differentiation. Cancer 68: 1754-1757, 1991.

23. Satoh Y, Hoshi R, Tsuzuku M, Ishikawa Y, Inamura K and Horai T: Cytology of pulmonary adenocarcinomas showing enteric differentiation. Acta Cytol 50: 250-256, 2006.

24. Nagasaka T, Sasamoto H, Notohara K, Cullings HM, Takeda M, Kimura K, Kambara T, MacPhee DG, Young J,Leggett BA, et al: Colorectal cancer with mutation in BRAF, KRAS, and wild-type with respect to both oncogenes showing different patterns of DNA methylation. J Clin Oncol 22: 4584-4594, 2004.

25. Moran T, Wei J, Cobo M, Qian X, Domine M, Zou Z, Bover I, Wang L, Provencio M, Yu L, et al; Spanish Lung Cancer Group; French Lung Cancer Group; Comprehensive Cncer Centre of Drum Tower Hospital in Nanjing: Two biomarker-directed randomized trials in European and Chinese patients with nonsmall-cell lung cancer: The BRCA1-RAP80 expression customization (BREC) studies. Ann Oncol 25: 2147-2155, 2014.
26. Bonanno L, Costa C, Majem M, Favaretto A, Rugge M and Rosell R: The predictive value of BRCA1 and RAP80 mRNA expression in advanced non-small-cell lung cancer patients treated with platinum-based chemotherapy. Ann Oncol 24: 1130-1132, 2013

27. Olaussen KA, Dunant A, Fouret P, Brambilla E, André F, Haddad V, Taranchon E, Filipits M, Pirker R, Popper HH, et al; IALT Bio Investigators: DNA repair by ERCC1 in non-small-cell lung cancer and cisplatin-based adjuvant chemotherapy. N Engl J Med 355: 983-991, 2006.

28. Reynolds C, Obasaju C, Schell MJ, Li X, Zheng Z, Boulware D, Caton JR, Demarco LC, O'Rourke MA, Shaw Wright G, et al: Randomized phase III trial of gemcitabine-based chemotherapy with in situ RRM1 and ERCC1 protein levels for response prediction in non-small-cell lung cancer. J Clin Oncol 27: 5808-5815, 2009.

29. Bepler G, Sommers KE, Cantor A, Li X, Sharma A, Williams C, Chiappori A, Haura E, Antonia S, Tanvetyanon T, et al: Clinical efficacy and predictive molecular markers of neoadjuvant gemcitabine and pemetrexed in resectable non-small cell lung cancer. J Thorac Oncol 3: 1112-1118, 2008.

30. André T, Bensmaine MA, Louvet C, François E, Lucas V, Desseigne F, Beerblock K, Bouché O, Carola E, Merrouche Y, et al: Multicenter phase II study of bimonthly high-dose leucovorin, fluorouracil infusion, and oxaliplatin for metastatic colorectal cancer resistant to the same leucovorin and fluorouracil regimen. J Clin Oncol 17: 3560-3568, 1999.

31. Saltz LB, Cox JV, Blanke C, Rosen LS, Fehrenbacher L, Moore MJ, Maroun JA, Ackland SP, Locker PK, Pirotta N, et al: Irinotecan plus fluorouracil and leucovorin for metastatic colorectal cancer. Irinotecan Study Group. N Engl J Med 343: 905-914, 2000.

32. Huang K, Vaughn DJ, Shaw LM, Recio A, Bonner HS and Haller DG: A phase II trial and pharmacokinetic analysis of 96-hour infusional paclitaxel in patients with metastatic colorectal cancer. Am J Clin Oncol 21: 548-552, 1998. 